\title{
Retraction Note to: Simulation of air environment and sports development in coastline cities based on high-resolution image processing system
}

\author{
Juan Liang ${ }^{1}$
}

Published online: 12 November 2021

(c) Saudi Society for Geosciences 2021

Retraction Note to: Arabian Journal of Geosciences (2021) 14: 962

https://doi.org/10.1007/s12517-021-07200-5

The Editor-in-Chief and the Publisher have retracted this article because the content of this article is nonsensical. The peer review process was not carried out in accordance with the Publisher's peer review policy. The author has not responded to correspondence regarding this retraction.

The original article can be found online at https://doi.org/10.1007/ s12517-021-07200-5.

\section{Juan Liang}

liangjuan9832@163.com

1 Physical Education Department, Zhengzhou Tourism

College, Zhengzhou 457000, China 